\title{
REPRESENTAÇÕES DE AMOR CORTÊS E CAVALARIA EM AMADIS DE GAULA
}

\section{COURTLY LOVE AND CHIVALRY REPRESENTATIONS IN AMADIS OF GAUL}

Juliane Terres ${ }^{1}$

Resumo: Amadis de Gaula, uma novela de cavalaria do século XIV cujo sucesso e alta circulação perdurou por séculos, apresenta-nos sua versão particular do modelo cortesão e cavaleirístico. Através de trechos selecionados, poderemos observar: elementos que se repetem ao longo dessa narrativa, e que se classificam como componentes característicos destes modelos; como é construída a imagem do cavaleiro perfeito; e como se dá a relação dos personagens dentro da lógica cortesã.

Palavras-Chave: Amadis de Gaula; novela de cavalaria; literatura medieval; amor cortês; cavalaria.

Abstract: Amadis of Gaul, a fourteenth century chivalric novel whose success and high circulation lasted for centuries, gives us its particular version of the courtly and chivalrous model. Through selected passages, we will be able to observe: elements that recur throughout this narrative, and that are classified as characteristic components of these models; how the image of the perfect knight is built; and how is the relationship of the characters within the courtly logic.

Keywords: Amadis of Gaul; chivalric romance; medieval literature; courtly love; cavalry.

\section{Introdução}

O que mestre Nicolau primeiro lhe pôs nas mãos foram os quatro de Amadis de Gaula.

\footnotetext{
${ }^{1}$ Aluna de graduação em História da Universidade Federal do Paraná.
} 
- Parece coisa de mistério esta! - disse o cura - porque, segundo tenho ouvido dizer, este livro foi o primeiro de cavalarias que em Espanha se imprimiu, e dele procederam todos os mais; por isso entendo que, por dogmatizador de tão má seita, sem remissão o devemos condenar ao fogo.

— Não senhor - disse o barbeiro — também eu tenho ouvido dizer que é o melhor de quantos livros neste gênero se têm composto; e por isso, por ser único em sua arte, se lhe deve perdoar.

- Verdade é - disse o cura; - por essa razão deixemo-lo viver por enquanto (CERVANTES, 2005: 44).

Este trecho de Dom Quixote nos mostra o quanto suas personagens, e talvez o próprio Miguel de Cervantes, prezavam $O$ Amadis, nomeando-o o mais antigo livro de cavalaria impressa e também o melhor de sua categoria. A primeira informação não é totalmente correta, uma vez que se têm notícias de uma impressão de Tirant lo Blanch em 1490, enquanto a primeira impressão do Amadis que conhecemos data de 1508 (ALBERTO, 2010: 13). Quanto à segunda informação, sendo apologia vinda de um dos baluartes da literatura espanhola, de pouco nos vale tentar refutá-la. Ela nos indica, porém, a reverberação que a história encontrou no público. Dom Quixote possuía os quatro livros do Amadis de Gaula, assim como As Sergas de Esplandião, um quinto livro acrescentado por Garcí Rodriguez Montalvo posteriormente, e também outras novelas de cavalaria inspiradas no Amadis. Estas últimas, junto com o quinto livro, foram condenadas à fogueira pelo cura, mas o Amadis foi perdoado por ser o "melhor" e "único" em sua categoria (CERVANTES, 2005: 44-45).

Devido ao seu sucesso, tão bem ilustrado por Cervantes, Amadis de Gaula teve inúmeras cópias manuscritas e impressas circulando por 
séculos. A versão aqui utilizada foi impressa em 1531, em Sevilha, baseada no manuscrito de Garcí Rodriguez Montalvo (1440-1504), sendo a versão mais antiga da novela que se encontra completa. ${ }^{2}$ Montalvo não é o autor da novela, mas se temos um registro completo dela hoje, nós o devemos à ele, que se dedicou em escrever sua versão "corrigida" a partir de escritos "corruptos e mal compostos em antigo estilo", "eliminado muitas palavras supérfluas e acrescentando outras de estilo mais polido e elegante", acrescentando ainda um quinto livro - "A Sergas de Esplandião" - aos quatro originais. Não se conhecem muitas informações sobre a vida de Montalvo, mas sabemos que ele viveu na segunda metade do século XV, e que a primeira versão impressa da sua transcrição de Amadis foi produzida em 1508, em Saragoça (LOPES, 2007: 163). Porém, tanto desta quanto de muitas outras edições, restam-nos apenas fragmentos, sendo poucas as edições completas da obra.

Entre a publicação da mencionada primeira edição conhecida (em 1508) e 1587 foram feitas outras trinta edições e traduções, além de inúmeras continuações e complementações. Isso reforça a ideia de popularidade da novela que se aproveitou da facilidade e menor custo propiciados pela (então recente) criação de Gutenberg para a impressão de livros. Podendo assim, ser considerada um dos primeiros best-sellers da História. Além da compilação de Montalvo, restam apenas quatro fragmentos em castelhano das primeiras décadas do século $\mathrm{XV}$, a partir das quais chegou-se à conclusão de que Montalvo teria suprimido mais par-

\footnotetext{
${ }^{2}$ Parte desta versão foi traduzida para o português pela Professora Graça Videira Lopes, e esta tradução também será utilizada aqui.
} 
tes do original que o complementado (ALBERTO, 2010: 14).

Sendo determinado que Montalvo não é o autor, questiona-se quem o é, e chegamos assim ao impasse da questão-problema das origens e da autoria de Amadis de Gaula. O manuscrito original não sobreviveu para nos oferecer seu testemunho, entretanto, infere-se que o relato inicial seja do século XIV.

Sendo a obra admirável que é, a honra de reclamá-la sua é disputada há tempos por portugueses e espanhóis, e até por franceses. Não cabendo aqui opinar sobre os méritos de cada um, procuramos observar seus argumentos. Os franceses alegam que a ambientação da narrativa favorece a teoria da origem francesa, localizando Gaula na França. A maioria dos pesquisadores do assunto, porém, sequer menciona essa possibilidade, descartando tal argumento. Os defensores da origem castelhana - como Juan Manuel Cacho Blecua (século XX) - tem a seu favor: 1) o fato de os únicos manuscritos encontrados estarem em castelhano, o que indicaria um autor castelhano, embora não se saiba sua identidade; 2) o fato de que a edição de 1508 foi impressa em Saragoça (ALBERTO, 2010: 15).

Os que defendem a origem portuguesa - como Teófilo Braga (1843-1924), Manuel Rodrigues Lapa (1897-1989) e Afonso Lopes Vieira (1878-1946) -, se valem de que: 1) Gomes Eanes de Zurara (1410-1474), o sucessor de Fernão Lopes (1380/1390-1460) como cronista da Livraria Real, atribuiu a autoria do Amadis a Vasco de Lobeira (século XIII) em 1460; 2) o poema feito por Amadis à Oriana, as Lais de Leonoreta, se encontra também no Cancioneiro da Biblioteca Nacio- 
nal de Lisboa, sendo aí atribuído ao trovador português João Lobeira, que trovou nos reinados de D. Afonso III (1210-1279) e D. Dinis (12611325); 3) há a presença de um D. Afonso de Portugal na obra (ALBERTO, 2010: 15). Alguns historiadores sugerem ainda que João Lobeira e Vasco de Lobeira seriam pai e filho, de forma que este deu continuidade ao que aquele havia iniciado (ALMEIDA, 2010: 49-50).

Independentemente de sua origem mais especifica, a obra se caracteriza como ibérica, sendo que as aventuras e a coita de Amadis povoaram o imaginário de seus leitores (e ouvintes) e permanecem até hoje como grandes exemplares do amor cortês e dos ideais cavalheirescos. Para compreender como isso se dá na obra, faz-se necessário um rápido resumo.

\section{A narrativa}

A história é relatada do ponto de vista de um narrador onisciente, que vê a todos e sabe o que se passa em suas mentes, mas não toma ação dentro da trama. Este narrador escolhe os fatos que são contados ao leitor e também a sequência em que são apresentados, por vezes, não seguindo uma ordem cronológica. Ou seja, em alguns momentos, o narrador pausa a narrativa do que se passa com uma personagem para nos contar o que sucedeu dias antes com outra, como pode se observar nestes trechos:

Aqui deixa o autor de contar isto, porque em seu lugar merecido se encontrará o que este Galaor fez, e torna a contar o que aconteceu ao Donzel do Mar depois que do rei Periom e da Donzela da Dinamarca e do castelo do velho partiu (MONTALVO, 2007: 
Cadernos de Clio, Curitiba, v. 6, nº. 2, 2015

46).

$\mathrm{O}$ autor aqui torna a contar do rei Periom e de sua amiga Elisena (MONTALVO, 2007: 26).

O autor aqui deixa de falar do Donzel do Mar e torna a falar de D. Galaor, seu irmão, que o gigante tinha levado (MONTALVO, 2007: 45).

$\mathrm{O}$ autor deixa aqui de contar isto, e torna a falar de Amadis e deste Galaor dirá a seu tempo (MONTALVO, 2007: 90).

El autor aquí deja de hablar de eso para lo contar en su lugar y torna a Amadís (MONTALVO, 1531: 170).

Há aqui dois "autores”, Montalvo e o autor original da novela, de quem não se tem conhecimento, e a quem Montalvo se refere na terceira pessoa. O narrador teria conhecimento de tudo que o autor original contou, e como o fez. Ou ao menos é o que ele tenta passar ao leitor.

O relato começa com os pais de Amadis: o rei Periom de Gaula e Elisena, filha do rei Garinter da Pequena Bretanha; narrando como se conheceram, enamoraram-se um do outro e desfrutaram desse amor às escondidas, auxiliados por Darioleta, dama de Elisena. Tendo D. Periom partido para defender seu reinado, Elisena se descobre grávida e se vê forçada a abandonar a criança, que é colocada no rio dentro de uma arca, juntamente com a espada e o anel que D. Periom deixara e com uma carta que a identificava. O bebê é encontrado por Gandales, que o cria junto com seu filho Gandalim - que acabará por acompanhar Amadis em suas aventuras, como seu escudeiro. Ao crescer, o Donzel do Mar - assim chamado por ter sido encontrado no mar, e por não se saber seu nome - faz-se notar pela sua beleza e pelo talento que demonstra em 
tudo que se empenha. Isso encanta a rainha da Escócia (irmã de Elisena), fazendo com que ele seja levado à corte do rei escocês Languines. Ali ele conhece a filha do rei da Dinamarca, Oriana, por quem se enamora. Buscando então se provar digno de sua dama, ele se faz nomear cavaleiro pelo rei Periom - sem que um ou o outro soubessem que eram pai e filho - e sai ao mundo empregando seus valores cavaleirescos. Entre seus vários feitos e aventuras, acaba por descobrir sua real origem e é reconhecido por seus pais - que haviam se casado, e desfruta de seu amor com Oriana, do qual nasce Esplandian. ${ }^{3}$

\section{Literatura e Cavalaria}

Devemos lembrar de questionar a fonte histórica dentro do que ela pode nos responder e, em se tratando de uma fonte literária, devemos iniciar tais questionamentos com os motivos que levaram ao seu registro, os locais por onde circulou e as pessoas que tiveram acesso a ela (BORGES, 2010). Nem sempre obteremos respostas satisfatórias, mas podemos fazer algumas reflexões pertinentes. Lembrando que durante a Idade Média os relatos orais eram mais comuns que os escritos, é possível imaginar que a história de Amadis tenha circulado oralmente antes (e depois) de ser registrada em papel. E apesar de sua popularidade, é provável que seu conhecimento fosse mais restrito à nobreza e às cortes, pois, ainda que a imprensa tenha barateado o custo da produção dos livros, eles continuavam não sendo acessíveis a todas as camadas da

\footnotetext{
${ }^{3}$ O poeta português Afonso Lopes Viera (1878-1946) fez uma versão reduzida da novela, cortando os elementos que lhe caracterizavam como "de cavalaria", transformando-a num romance.
} 
sociedade. Já os relatos orais podem ter facilmente penetrado tais camadas (ALBERTO, 2010).

Pensando ainda nessa confluência entre a oralidade e a escrita, podemos observar as rupturas e as continuidades entre a poesia das cantigas medievais e a prosa das novelas de cavalaria. Ainda que a prosa se dedique mais intensamente à narrativa e aos detalhes, ela ainda apresenta muito da poesia, principalmente nos temas abordados, como a coita amorosa, o loor (louvor) à dama, os valores cavaleirescos e nobres, todos os quais podemos observar no Amadis.

Quando lemos Amadis de Gaula é fácil perceber a associação feita entre cavalaria e nobreza, pois apesar de Amadis ter sido feito cavaleiro antes de descobrir sua linhagem, todos os outros cavaleiros da narrativa vêm de famílias nobres. No entanto, essa conexão não surge com a cavalaria, mas é ligada à ela por volta do século XIII (FLORI, 2005: 123). Se considerarmos que o cavaleiro precisava de recursos para se armar e manter um cavalo, a participação camponesa nessa empreitada se torna difícil, ou mesmo impossível.

Por volta do século XI a cavalaria começa a ser sacralizada pela Igreja Católica. Isto pode parecer contraditório de relance, afinal a Igreja sempre foi declaradamente contra a violência. Mas um olhar mais detalhado do contexto nos faz perceber a lógica deste aparente paradoxo. $\mathrm{O}$ século XI marca o fim de incursões guerreiras, e uma melhora no clima europeu, o que contribuiu para melhores colheitas e um crescimento demográfico, o que resultou em guerras privadas por terras e heranças. Estas prejudicavam a Igreja, que procurou amenizá-las com a Pax Dei, a 
Tregua Dei, proibindo a violência contra aqueles que dela não podiam se defender, sob pena de excomunhão (FLORI, 2005: 134). Com estas e outras medidas a Igreja procurou sacralizar o cavaleiro, tornando-o um defensor dos valores católicos, que poderia empreender a violência em nome da fé cristã, mas que deveria se confessar para se expurgar desse pecado.

Nos séculos XII e XIII o aumento demográfico dos séculos anteriores resulta numa estrutura familiar nobre perigosa para a ordem social. Para evitar a dispersão de seus bens, os primogênitos eram os principais herdeiros, fazendo com que os filhos seguintes tivessem de optar por alternativas como juntar-se ao clero, encontrar um casamento lucrativo, ou então procurar sua sorte algures, através das guerras e pilhagens. Aqueles que escolhiam esta última alternativa eram os responsáveis pela atribulação da época. Com intuito de amenizar essa situação, procura-se criar regras de comportamento para esse grupo. Assim vemos a elaboração do cavaleiro cortês, que sendo nobre e bom cristão, tem limites para a sua violência, que deve ser empregada contra os maus para defender os bons. Isso contribuiu para a diminuição da instabilidade social e da violência (ZIERER, 2009: 307).

A essência das novelas de cavalaria está nas inúmeras batalhas e guerras descritas em detalhes, nas aventuras de personagens maravilhosos que se envolvem em façanhas admiráveis. Não precisamos ler mais do que algumas páginas do Amadis para encontrar esses elementos:

Ele voltou a cabeça e viu o cavaleiro com quem antes justara, e outro cavaleiro com ele, e tomando as suas armas, foi contra eles, 
que traziam as lanças baixas e ao melhor correr dos seus cavalos. $\mathrm{E}$ os das tendas viram-no ir tão aposto na sela que ficaram maravilhados. E certamente podeis crer que no seu tempo não houve cavaleiro que mais aposto na sela parecesse, nem mais formoso justasse, tanto que em algumas partes onde ele se queria encobrir foi descoberto por isso; e os dois cavaleiros feriram-no com as suas lanças no escudo que lho amolgaram, mas o arnês não, que era forte; e as lanças foram quebradas, e ele feriu o primeiro que antes tinha derrubado e embateu nele tão fortemente que deu com ele em terra e quebrou-lhe um braço e ficou como morto; e o Donzel perdeu a lança, mas deitou logo mão à espada e foi contra o outro que o feria, e deu-lhe por cima do elmo, assim que a espada chegou-lhe à cabeça, e quando a puxou, quebraram-se os laços e tirou-lho da cabeça; e alçou a espada para o ferir e o outro alçou o escudo, e o Donzel do Mar deteve o golpe, e passando a espada para a mão esquerda, agarrou-lhe o escudo e tirou-lho do colo e deu-lhe com ele por cima da cabeça, que o cavaleiro caiu por terra atordoado (MONTALVO, 2007: 58-59).

\section{O Amor}

No Amadis - e nas novelas de cavalaria em geral - o amor é um elemento importante na narrativa, mas não é seu foco. Ele aparece mais como um pano de fundo, uma justificativa primordial que leva o cavaleiro às suas aventuras. Aqui entramos na discussão do conceito de amor cortês, já que fazer as vontades da dama e honrar seu nome com vitórias bélicas fazem parte desse imaginário, e também justifica parcialmente porque Amadis corre o mundo empregando os valores em que acredita.

O conceito de amor cortesão não é uma unanimidade entre os historiadores. Régnier-Bohler, aplica o conceito ao amor de um cavaleiro por uma dama casada, e portanto, inacessível, ou aos sentimentos de jovens que aspiram ao casamento (RÉGNIER-BOHLER, 2002: 48). Martin Aurell vê a dama como esquiva, quase inacessível, mas não con- 
sidera o aspecto adúltero visto por outros historiadores. Em seu conceito, a recusa da dama é mais uma das etapas ritualísticas pelas quais o amante precisa passar. Este rende tributo à dama, que lhe faz promesas, seguindo a lógica feudal. Aurell avalia que essa livre troca de consentimentos - do amante que escolhe a dama, e da dama que aceita o amante - contribuiu para a definição da natureza sacra do casamento, valorizando o amor d'élection, e marcando a mentalidade Ocidental (AURELL, 2002: 52). Duby compara o amor cortês a um jogo perigoso e excitante. Perigoso pois não podia ser descoberto, daí a necessidade da discrição, e excitante justamente por causa desse perigo. Assim como todo jogo, o amor cortês possuía regras e dependia do consenso dos jogadores. $\mathrm{O}$ amante faz cerco à dama, se ajoelha perante ela, prometendo não prestar serviço a nenhuma outra. Se a dama aceita - pelas regras do jogo, e também pela lógica dessa sociedade onde toda dádiva merece uma contradádiva - ela é obrigada a recompensar o amante. Essa recompensa, porém, deve ser feita por etapas dosadas, para manter o jogo e a discrição. Segundo Duby, essa relação se dava muitas vezes entre cavaleiros da corte e a senhora da casa, a mulher do senhor que eles serviam. Porém, o aspecto adúltero desse relacionamento fica reservado às exceções, já que dentro dessa dança amorosa lúdica, os cavaleiros estavam servindo ao senhor, e mostrando sua fidelidade a ele quando se submetiam à vassalagem amorosa com sua senhora (DUBY, 1994: 332).

Quanto aos simbolismos do amor cortês, os historiadores parecem concordar que a relação do casal se dá sob uma lógica feudal, a dama 
sendo a senhor ${ }^{4}$ recebe o cavaleiro como seu vassalo. Este lhe deve homenagem, o que pode abranger diferentes serviços ${ }^{5}$, como manter a relação e o nome da amada em segredo, fazer cantigas de loor a dama, ou se dedicar aos valores cavaleirescos em seu nome. E em troca, a dama oferecerá um benefício ${ }^{6}$ ao cavaleiro, o que pode ser desde uma palavra, uma mensagem, um olhar, um beijo, ou até a secreta relação carnal. O percurso que leva ao benefício, porém, é longo e sofrido, e leva o cavaleiro à coita ${ }^{7}$. O cavaleiro precisa se provar digno, vencer a provação da castidade, conter seu desejo, para que a dama lhe faça $\mathrm{bem}^{8}$. O amor, que exige a superação de obstáculos e paciência, atormenta o cavaleiro, que ora deseja a morte, ora se aproxima da loucura. Caso uma das partes não cumpra o que deve, surge o sentimento de saña ${ }^{9}$.

${ }^{4}$ Forma de tratamento dirigido à dama, "o genêro masculino se explica como (SPINA, 1921: 404).

${ }^{5} \mathrm{O}$ servir ou serviço, consiste no "conjunto de deveres do vassalo para com o suserano", mas dentro dos conceitos de amor cortês, "o serviço confundia-se de tal forma com o amor que ambas as palavras se tornaram sinonimas". Para cumprir com suas obrigações de vassalo, o amante deveria observar alguns preceitos como discrição e a dedicação (SPINA, 1921: 404).

${ }^{6} \mathrm{O}$ benefício ou bem, era a recompensa à qual o amante aspirava quando se dedicava a sua dama, e podia ser oferecido de diferentes maneiras, como "uma saudação, uma prova de simpatia. Às vezes (...) um beijo", até exigências mais sensuais. Na lógica cortesã, era um direito do amante, e um dever da dama (SPINA, 1921: 390).

${ }^{7}$ A coita se resume em pena, tormento ou sofrimento, pelo qual o amante deve passar antes de alcançar o benefício (SPINA, 1921: 367).

${ }^{8}$ Idem: benefício ou bem.

${ }^{9}$ O termo "saña" dispõem de algumas definições distintas, mas de acordo com o que vemos no Amadis, podemos mencionar duas: 1) a de Segismundo Spina, segundo a qual, saña, ou sanha, é a indignação da dama frente a desmesura de seu amado, ou por vezes os arrufos que se davam entre eles (SPINA, 1921: 
É possível observar todos esses elementos característicos do amor cortesão e da cavalaria em Amadis, que os atualiza, como aponta Moraes Alberto:

O Amadis de Gaula nos mostra uma cavalaria diferente, um tanto quanto superior, que conserva o lado espetacular da antiga, com suas leis e formalidades, mas transforma e enobrece seu espírito, deixando-a mais polida. Desaparece a rudeza da palavra e da obra, e são táteis as influências cortesãs ao ideal cavaleiresco que se completa no Amadis, e mostra a distância em que a obra se encontrava do meio popular, por onde originalmente é provável que tenha circulado na forma oral, ao menos em parte. Mas o principal no Amadis é sua nova concepção de amor, em uma época marcada pela moral e pela religiosidade. Este amor é uma adoração permanente, e Amadis e Oriana são ambos os protótipos dos perfeitos amantes, considerados ao mesmo tempo como cavaleiro e dama, um novo sistema de conduta, que contrasta às paixões adúlteras das narrativas celtas. Amadis é a epopeia da fidelidade amorosa (ALBERTO, 2010: 92).

Segundo Marcelino Pelayo, o autor de Amadis "fez alguma coisa mais que um livro de cavalaria à imitação dos poemas do ciclo bretão: escreveu a primeira novela idealista moderna e a epopeia da fidelidade amorosa, o código da honra e da cortesia, que disciplinou muitas gerações" (PELAYO, 1923: 11). Estas palavras de Pelayo e de Alberto refletem justamente a ideia de que esta novela não representava a sociedade em que foi escrita, mas que procurava estabelecer um ideal de comportamento, como tal sociedade deveria se portar.

Feitas tais considerações, refletimos então, mais detalhadamente

402); 2) a de Moraes Alberto, que liga o conceito às ideias de ira (no sentido de pecado capital) e loucura, vendo-o como uma "loucura furiosa" que impulsionava os atos corajosos dos cavaleiros (ALBERTO, 2010: 29). 
sobre estes aspectos à luz de alguns trechos escolhidos:

- Ai, Deus! Por que vos prougue de pôr tanta beleza nesta senhora e em mim tanta coita e dor por causa dela? Em forte ponto os meus olhos a olharam, pois que perdendo o seu lume, com a morte pagarão aquela grã loucura que no coração puseram (MONTALVO, 2007: 32).

- Ai, cativo Donzel do Mar, sem linhagem e sem bem, e como foste tão ousado de meter o teu coração e o teu amor em poder daquela que vale mais que as outras todas em bondade e formusura e em linhagem? Oh, cativo! Por qualquer destas três cousas não devia ser ousado o melhor cavaleiro do mundo de a amar, que mais é ela formosa do que o melhor cavaleiro em armas, e mais vale a sua bondade do que a riqueza do maior homem do mundo, e eu, cativo, que não sei quem sou, que vivo com trabalho de tal loucura que morrerei amando sem lho ousar dizer (MONTALVO, 2007: 56).

Viram-lhe os olhos vermelhos e as faces molhadas de lágrimas, assim que bem parecia que dormira pouco de noite, e sem falta assim era, que, lembrando-se da sua amiga, considerando a grande coita que por ela lhe vinha sem ter nenhuma esperança de remédio, outra coisa não esperava senão a morte (MONTALVO, 2007: 61).

- Ai, amigo Gandalim, como sofre meu coração! Se tu me amas, sabe que antes me aconselharias a morte que viver em tão grande coita, desejando o que não vejo. (...) Havia eu de valer, ou algum outro, tanto como aquela em quem todo o bem do mundo está? (MONTALVO, 2007: 97).

- Ai Deus! Onde está ali a flor do mundo? Ai, vila, como estais agora em grande altura por estar em ti aquela senhora que entre todas as do mundo não há par em bondade e formosura, e ainda digo que é mais amada do que todas aquelas que amadas são, e isto provarei eu ao melhor cavaleiro do mundo, se ela mo outorgasse!

Depois que sua senhora louvou, um tão grande cuidado lhe veio, que as lágrimas vieram-lhe aos olhos e, enfraquecendo-lhe o coração, caiu em grande pensamento, que todo estava entorpecido, 
de maneira que nem de si nem de outro sabia parte (MONTALVO, 2007: 96).

Nos trechos acima vemos a coita de Amadis, a consideração da morte como única solução para seu sofrimento, seu medo de não ser digno de sua dama devido à sua descendência desconhecida - aliás, nenhum homem no mundo seria digno de Oriana, a flor do mundo, "a mais formosa criatura que jamais se viu, tanto que foi a que 'sem par' se chamou, porque no seu tempo nenhuma houve que lhe fosse igual" (MONTALVO, 2007: 30). Esta idealização da personagem de Oriana não parte apenas da perspectiva de Amadis, o cavaleiro apaixonado. Outras personagens e o próprio narrador parecem concordar com a incomparável beleza de Oriana, como mostra a frase acima, nas palavras do narrador. Nos trechos seguintes podemos observar a característica feudal do amor cortês, onde o homem se faz vassalo de sua dama, sua senhor, lhe prestando serviço em troca de benefício, ou mercê:

- Ai, Deus! - disse Amadis - como servirei eu a esta senhora a grande mercê que me faz agora? (MONTALVO, 2007: 108)

- Senhora, se minha discrição não bastar para satisfazer a mercê que me dizeis e a que me fizestes no recado da Donzela da Dinamarca, (...) e se eu, minha senhora, fosse tão digno ou os meus serviços o merecessem, pedir-vos-ia piedade para este tão atribulado coração, antes que ele todo com lágrimas seja desfeito; e a mercê que vos, senhora, peço não para meu descanso, que as cousas verdadeiramente amadas quanto mais delas se alcança muito mais o desejo e o cuidado aumenta e cresce, mas porque acabando tudo, acabaria aquele que não pensa noutra coisa senão em vos servir (MONTALVO, 2007: 109).

Aqui vemos um serviço prestado por Amadis à Oriana: a discri- 
ção; o manter em segredo a relação. Mas ao longo da narrativa este serviço também aparece nas obras cavaleirescas empregadas, de forma que Amadis se empenha e luta em nome de Oriana, dedicando a ela suas vitórias.

Nos momentos em que há o loor à dama podemos também observar outro aspecto interessante da poesia e da prosa medievais: a atribuição de características físicas reflete a condição social, os vícios e virtudes das pessoas. Dessa forma, em geral, as pessoas boas e nobres são belas, e as más são feias ou deformadas. Por isso vemos Amadis formoso e talentoso para tudo o que se empenha em fazer, afinal ele é descendente de reis e um cavaleiro valoroso.

\section{Considerações Finais}

Os exemplos acima são uma pequena parte das representações do amor cortês e da cavalaria que podem ser encontrados n'O Amadis. Tais representações não são retratos fiéis do cotidiano da sociedade da época, mas procuram estabelecer modelos de comportamento elevado para uma comunidade que atravessava um período de mudanças estruturais - a Península Ibérica enfrentava uma conturbada fase de trocas dinásticas em todos os seus reinos. Devido à esta não-correspondência entre os valores da realidade e da ficção em Amadis, a obra foi considerada anacrônica e saudosista, já que aparentava celebrar valores de séculos passados, que já não condiziam com a sociedade ibérica do século XVI. No entanto, os modelos da obra não procuram representar a realidade de nenhuma sociedade ou época, mas apresentar ideais a serem copiados. 
Em contrapartida temos o grande sucesso da obra, o que nos sugere que apesar desses temas não representarem essa sociedade, ainda havia uma demanda por parte desta em relação a tais temas. Ou seja, a obra foi bem-sucedida porque atendia às expectativas de seu público. De forma que Amadis de Gaula foi, e continua sendo, um grande exemplar cavaleiresco cortesão.

\section{Fontes}

MONTALVO, Garcí Rodriguez de. Los quatro libros de Amadis de Gaula. Sevilha, $1531 . \quad$ Disponível em: <http://www.wdl.org/pt/item/7330/>. Acesso em: outubro de 2014.

Amadis de Gaula. Trad. Graça Videira Lopes, 2007. Disponível em:

<http://www.fcsh.unl.pt/docentes/gvideiralopes/index_ficheiros/amadis T.pdf>. Acesso em: maio de 2014.

\section{Bibliografia}

ALBERTO, Rodrigo Moraes. A Saña no ideal cavaleiresco ibérico do final da Idade Média a partir da novela "O Amadis de Gaula”. Disponível

em: <http://www.lume.ufrgs.br/bitstream/handle/10183/28946/000774554.p df? sequence $=1>$. Acesso em: outubro de 2014.

. O Amadis de Gaula e o ideal cavalheiresco ibérico. Dis-

ponível em: <http://seer.ufrgs.br/index.php/aedos/article/view/22302/13119>. Acesso em: maio de 2014.

ALMEIDA, Isabel Adelaide. "Amadis de Gaula”. In: LANCIANI, Giuseppe, TAVANI, Giulia. Dicionário da Literatura Medieval Galega e Portuguesa (2 ed.). Caminho: Lisboa, 2000, pp. 49-50. 
AURELL, Martin. "Amour Courtois". In: GUAYARD, C., LIBERA, A., ZINK, M. Dictionnaire du Moyen Âge. Paris: PUF, 2002, p. 52.

BORGES, Valdeci Rezende. "História e Literatura: Algumas Considerações". In: Revista de Teoria da História. Ano 1, n.3. Goiás: Editora da Universidade Federal de Goiás, 2010, pp. 94-109. Encontrado em: $<$ http://www.historia.ufg.br/up/114/o/ARTIGO_BORGES.pdf >. Acesso em: novembro de 2014.

CERVANTES, Miguel de. Dom Quixote de La Mancha - Primeira Parte. Tradução de Francisco Pereira e Sá Coelho de Castilho. eBooksBrasil: 2005, cap VI, p. 44. Disponível em: <http://www.dominiopublico.gov.br/download/texto/eb00008a.pdf>. Acesso em: outubro de 2014.

D’ONOFRIO, Salvatore. Forma e sentido do texto literário. São Paulo: Ática, 2007.

DUBY, Georges. A Sociedade Cavaleiresca. São Paulo: Martins Fontes, 1989.

. "O modelo cortês". In: DUBY, G., PERROT, M. História das Mulheres no Ocidente.

FINAZZI-AGRÒ, Ettore. "Novela de Cavalaria" In: LANCIANI, Giuseppe, TAVANI, Giulia. Dicionário da Literatura Medieval Galega e Portuguesa (2a ed.). Caminho: Lisboa, 2000, pp. 475-477.

FLORI, Jean. A Cavalaria: A origem dos nobres guerreiros da Idade Média. São Paulo: Madras, 2005.

LOPES, Graça Videira. "Sobre Amadis de Gaula - breve nota". In: MONTALVO, Garcí Rodriguez de. Amadis de Gaula. Trad. Graça Videira Lopes, 2007. Disponível em: <http://www.fcsh.unl.pt/docentes/gvideiralopes/index_ficheiros/amadis T.pdf $>$. Acesso em: maio de 2014.

LOURENÇO, Helena. Do amor e da Soledad no Amadís de Gaula: 
Cadernos de Clio, Curitiba, v. 6, nº. 2, 2015

ressonâncias no teatro vicentino. Disponível em: <http://ler.letras.up.pt/uploads/ficheiros/7657.pdf>. Acesso em: outubro de 2014.

LOYN, H.R. Dicionário da Idade Média. Rio de Janeiro: Jorge Zahar, 1997.

MONGELLI, Lênia Márcia, VIEIRA, Yara Frateschi. A estética medieval. Cotia: Íbis, 2003.

PELAYO, Marcelino Menéndez. "Prefácio". In: VIERA, Afonso Lopes. $O$ Romance de Amadis. Lisboa: Oficinas Gráficas da Biblioteca Nacional de Lisboa, 1923.

RÉGNIER-BOHLER, Danielle. "Amor Cortesão". In: LE GOFF, Jacques, SCHMITT, Jean-Claude. Dicionário Temático do Ocidente Medieval. Bauru, SP: EDUSC, 2002.

SARAIVA, António José, LOPES, Oscar. História da Literatura Portuguesa. Porto: Porto, s/d.

SPINA, Segismundo. A Lírica Trovadoresca. São Paulo: Editora da Universidade de São Paulo, 1996.

Edições, 1973.

Iniciação na Cultura Literária Medieval. Rio de Janeiro: Grifo . Presença da Literatura Portuguesa - era medieval. Rio de Janeiro: Bertrand Brasil, 1991.

ZIERER, Adriana Maria de Souza. "O cavaleiro cristão n'A Demanda do Santo Graal e n'O Livro da Ordem de Cavalaria". In: OLIVEIRA, Terezinha (org.). Educação, História e Filosofia no Ocidente: Antiguidade e Medievo. Itajaí: Univali Editora, 2009.

Recebido em: 26/05/2015 Aceito em: 29/09/2015 